\title{
Location of Nitrogenase and Ammonia-assimilatory Enzymes in Bacteroids of Rhizobium leguminosarum and Rhizobium lupini
}

\author{
By K. PLANQUÉ, I. R. KENNEDY, ${ }^{*}$ G. E. DE VRIES, \\ A. QUISPEL AND A. A. N. VAN BRUSSEL \\ Botanical Laboratory, Research Group of Nitrogen Fixation, \\ State University, Leiden, The Netherlands
}

(Received 2 March 1977)

\begin{abstract}
Cytoplasmic and membrane fractions were isolated from bacteroids of Rhizobium leguminosarum and $R$. lupini disrupted by lysozyme-induced lysis and sonication. The release of nitrogenase, glutamine synthetase (EC 6.3.I.2), glutamate synthase (EC 2.6. I.53) and glutamate dehydrogenase (EC I.4.I.4) activities was compared with NADH oxidase and 3-hydroxybutyrate dehydrogenase (EC I I. I . 30) activities as markers for membrane and cytoplasmic enzyme activities respectively. Nitrogenase was localized in the cytoplasm. Most of the glutamate dehydrogenase activity was released on lysozyme treatment of intact bacteroids although some was released from membrane fractions on sonication, indicating a very superficial localization. Glutamate synthase was present at very low levels in $R$. leguminosarum bacteroids; the level in $R$. lupini bacteroids was higher and the enzyme was probably weakly membrane-bound. About $95 \%$ of the glutamine synthetase activity was in the nodule cytosol, and the supernatant of washed bacteroids had a high specific activity; the remaining activity was unevenly distributed between soluble and membrane fractions.
\end{abstract}

\section{INTRODUCTION}

Bacteroids are the site of nitrogen fixation in nodules of leguminous plants (Kennedy, Parker \& Kidby, I966), and after short, pulsed exposures of intact nodules to ${ }^{15} \mathrm{~N}_{2}$ (Kennedy, I966 $a, b$ ) glutamate, glutamine and aspartate showed the highest enrichment with ${ }^{15}$ N. Subsequently glutamate synthase (Nagatani, Shimizu \& Valentine, I97I; Robertson, Warburton \& Farnden, I975b), glutamate dehydrogenase (Grimes \& Fottrell, 1966) and glutamine synthetase (Kennedy, 1973; Dunn \& Klucas, 1973) were found both inside and outside the bacteroids.

Bacteroids of Rhizobium leguminosarum are sensitive to lysis by lysozyme, but the freeliving bacteria require the addition of EDTA before they become sensitive to lysozyme, indicating that bacteroids have a modified outer membrane (van Brussel, 1973; van Brussel, Planqué \& Quispel, 1977). In free-living nitrogen-fixing Rhizobium japonicum and 'cowpea' Rhizobium most of the newly-fixed $\mathrm{NH}_{4}{ }^{+}$is exported out of the organism (O'Gara \& Shanmugam, 1976). If this occurs in bacteroids, the excreted ammonia could be converted to asparagine by a co-operative system comprising glutamine synthetase, glutamate synthase and asparagine synthetase (Scott, Farnden \& Robertson, 1976).

The levels of glutamine synthetase, glutamate synthase and glutamate dehydrogenase are controlled by the $\mathrm{NH}_{4}{ }^{+}$concentration in the culture medium in Klebsiella aerogenes (Tempest, Meers \& Brown, 1973) and several other bacteria including the free-living form of Rhizobium (Brown \& Dilworth, 1975). The levels of these enzymes were different in the

* Present address: Department of Agricultural Research, University of Sydney, Australia. 
bacteroid forms of five Rhizobium species investigated. This could indicate different ammonia levels inside the respective bacteroids or, more importantly, a different response in bacteroids to varying ammonia concentrations. The latter point could have important implications since glutamine synthetase has both an assimilatory and a regulatory role in nitrogen metabolism (Streicher et al., 1974). Glutamine synthetase is involved in the regulation of nitrogenase synthesis in Klebsiella pneumoniae (Tubb, 1974; Shanmugam \& Valentine, 1975). If a comparable control mechanism operates in Rhizobium, the differences in glutamine synthetase activities in different bacteroid species reported by Brown \& Dilworth (1975) could be explained if the ammonia-assimilating enzymes had a specific location inside the bacteroids which resulted in an ammonia excess in one part of the cell and an ammonia limitation in another.

To evaluate this possibility, we have attempted to determine the location of nitrogenase, glutamate dehydrogenase, glutamate synthase and glutamine synthetase by fractionating bacteroids into membranes and cytoplasm and comparing the release of these enzymes with NADH oxidase and 3-hydroxybutyrate dehydrogenase as markers for membrane-bound and cytoplasmic enzyme locations respectively (Osborn et al., 1972; Brown \& Dilworth, 1975).

\section{METHODS}

Plants and production of nodules. Yellow lupins (Lupinus luteus), field-grown at the State Forestry Nurseries at Baarn, The Netherlands, were inoculated with Rhizobium lupini; nodules were harvested 2 to 6 weeks before flowering. Green peas (Pisum sativum $\mathrm{cv}$. Rondo; Cebeco, Rotterdam, The Netherlands) were inoculated with Rhizobium leguminosarum strain AI7I, and were cultivated as described by Planqué \& van Brussel (1976); nodules were harvested at 21 days.

\section{Preparation of nodule fractions and bacteroids}

Root systems of lupin and pea plants were thoroughly washed with water. Bacteroids were released from the root nodules by homogenizing the root system in a Waring blendor for $2 \mathrm{~min}$ in a medium containing $0.05 \mathrm{M}$-potassium phosphate buffer $\mathrm{pH} 7.4,0.3 \mathrm{M}$-sucrose and $2 \%(\mathrm{w} / \mathrm{v})$ soluble polyvinyl pyrollidone $\mathrm{K} 9 \mathrm{O}$ (Fluka, Buchs, Switzerland). When nitrogenase activity was to be assayed, $\mathrm{O} \cdot \mathrm{I} \mathrm{mg}$ sodium dithionite $\mathrm{ml}^{-1}$ and $\mathrm{o} \cdot \mathrm{I} \mathrm{mg}$ dithiothreitol ml-1 were added, and the medium was sparged with $\mathrm{N}_{2}$ before adding the nodules. All subsequent operations were under $\mathbf{N}_{2}$.

Nodule cytosol. Large plant fragments and other debris were removed by filtration through cheese cloth, and centrifuging the filtrate at $500 \mathrm{~g}$ for $2 \mathrm{~min}$. Bacteroids, together with membranous plant material, were collected by centrifuging at $5000 \mathrm{~g}$ for $10 \mathrm{~min}$. The supernatant, designated nodule cytosol, was stored at $0^{\circ} \mathrm{C}$ or frozen under $\mathrm{N}_{2}$. It contained leghaemoglobin and other constituents of infected and uninfected cells of root tissue. All centrifugations were at $4{ }^{\circ} \mathrm{C}$.

Bacteroid preparation. The pellet obtained by centrifuging at $5000 \mathrm{~g}$ was resuspended and washed twice in sucrose/phosphate buffer using a buffer to pellet ratio of $10: I(v / v)$ and then centrifuged for Io min at $4000 \mathrm{~g}$. Phase contrast microscopy and electron microscopy of the supernatants, designated first and second wash supernatants, showed the absence of bacteroids although a considerable quantity of membranous material was present (Fig. I). The washed pellet was suspended in sucrose/phosphate buffer $\mathrm{pH} 7 \cdot 4$, and designated bacteroid suspension. All fractions were stored under $\mathrm{N}_{2}$; the wash supernatants were kept at $0^{\circ} \mathrm{C}$ or frozen.

\section{Preparation of bacteroid fractions}

Sonication. Suspensions of lupin bacteroids were sonicated for 2 to 3 min under a stream of $\mathrm{N}_{2}$ in an ice bath, using a Branson model $\mathrm{L}$ sonifier. The sonicate was separated into soluble and insoluble fractions by centrifuging at $105000 \mathrm{~g}$ for $30 \mathrm{~min}$ at $4{ }^{\circ} \mathrm{C}$. Suspensions of pea bacteroids were sonicated for six periods of $15 \mathrm{~s}$ with intermittent cooling. Separation into soluble and insoluble fractions was achieved by centrifuging the supernatant at $50000 \mathrm{~g}$ for $20 \mathrm{~min}$. The supernatant and pellet fractions were designated bacteroid sonicate supernatant and bacteroid sonicate pellet.

Lysozyme lysis. Osmotic shock caused extensive lysis of bacteroids after the bacteroid suspension had been incubated with lysozyme. The techniques used were based on those employed by van Brussel (1973). Freshly-prepared bacteroid suspension $(20 \mathrm{ml})$ in $0.05 \mathrm{M}$-potassium phosphate buffer $\mathrm{pH} 7 \cdot 0$, containing $0.3 \mathrm{M}$-sucrose was incubated at $30^{\circ} \mathrm{C}$ for $30 \mathrm{~min}$ with $\mathrm{I} \cdot 0 \mathrm{mg}$ lysozyme $\mathrm{ml}^{-1}$ (Sigma, grade I). At the end of the 
incubation the bacteroids were removed by centrifuging at $5000 \mathrm{~g}$ for Io min to give a bacteroid-free supernatant (designated lysozyme incubation supernatant) which was removed and stored under $\mathrm{N}_{2}$. The pellet was then 'shocked' by rapid resuspension in $20 \mathrm{ml}$ de-aerated distilled water. The resulting preparation of completely lysed bacteroids was separated into a membrane and a soluble fraction (designated lysozymeshock pellet and lysozyme-shock supernatant) by centrifuging at $105000 \mathrm{~g}$. Under phase contrast microscopy, transparent bacteroid forms were seen in the lysozyme-shock pellet; these were comparable to ghost preparations of Salmonella (Obsorn et al., 1972). The ghosts can be separated into cytoplasmic membrane and outer membrane preparations (K. Planqué, A.v. d. Werf, T. v. Slogteren, unpublished results). Sonication of the lysozyme-shock pellet for $45 \mathrm{~s}$ followed by centrifuging at $50000 \mathrm{~g}$ for $20 \mathrm{~min}$ resulted in a lysozymeshock sonication pellet and a lysozyme-shock sonication supernatant.

\section{Enzyme assays}

Nitrogenase. The nitrogenase activity of bacteroids and extracts was measured by the acetylene reduction technique as described by Akkermans (1971). Assays on intact bacteroids routinely used $12 \mathrm{ml}$ rubber-sealed

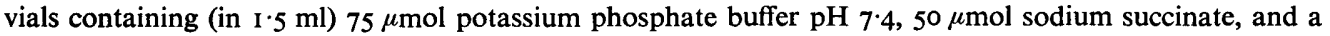
suitable quantity of bacteroids in phosphate buffer, under $\mathrm{O} \cdot \mathrm{I}$ atm $\mathrm{O}_{2}$ and $0.2 \mathrm{~atm}$ acetylene in $\mathrm{N}_{2}$. Extracts, and sometimes whole bacteroids, were assayed in a similar manner but anaerobically using an ATPgenerating system and sodium dithionite assay as described by Yates \& Planqué (I975).

Glutamine synthetase (EC 6.3.1.2). Both $\gamma$-glutamyl transferase activity and synthetase activity were measured. Transferase activity was assayed as described by Shapiro \& Stadtman (1970), except that 2-(N-2hydroxyethylpiperazin- $N^{\prime}$-yl)ethanesulphonic acid (HEPES) buffer $\mathrm{pH} 7.3$, was used instead of imidazole/ HCl. Synthetase activity was assayed as described by Rowe et al. (1970) except that ATP was replaced by an ATP-generating system comprising (per $0.4 \mathrm{ml}$ assay mixture) $\mathrm{I} \cdot 8 \mu \mathrm{mol} \mathrm{Na}{ }_{2}$ ATP, $250 \mu \mathrm{mol}$ creatine phosphate and $90 \mu \mathrm{g}$ creatine kinase. The production of $\gamma$-glutamyl hydroxamate was determined spectrophotometrically by calibration against authentic material. Under the conditions used $2.5 \mathrm{~mol}$ product had an $E_{540}$ of 0.001 .

NADH oxidase, glutamate dehydrogenase (EC I .4 I .4), glutamate synthase (EC 2.6. I .53) and 3-hydroxybutyrate dehydrogenase (EC I I I I.30). These enzymes were assayed spectrophotometrically at $340 \mathrm{~nm}$ by measuring NADH oxidation. All assays contained (in $2 \mathrm{ml}$ ) $50 \mu \mathrm{mol} \mathrm{HEPES} \mathrm{buffer} \mathrm{pH} 7.5,0.2 \mu \mathrm{mol}$ NADH, and enzyme preparation. The NADH oxidase activity was measured, and then various compounds were added to the assay mixture to allow measurement of other enzyme activities: $20 \mu \mathrm{mol} \mathrm{NH}_{4} \mathrm{Cl}$ and $20 \mu \mathrm{mol} 2$-oxoglutarate $\mathrm{pH}_{17}^{\prime} \cdot 0$ were added to assay glutamate dehydrogenase activity; $20 \mu \mathrm{mol} 2$-oxoglutarate and $2 \mu \mathrm{mol}$ glutamine to assay glutamate synthase activity; and $2 \mu \mathrm{mol}$ acetoacetate to assay 3-hydroxybutyrate dehydrogenase activity.

All assays were corrected for non-specific NADH oxidation measured in the absence of only the $\mathrm{NH}_{2}$ donor. No difference in this activity was observed between enzyme preparations which were fresh, stored, or passed over Sephadex G-25 $(2.5 \times 30 \mathrm{~cm}$ column $)$ to remove inhibitors and endogenous substrates. The ammonia-assimilating enzymes were assayed within $3 \mathrm{~h}$ of the start of nodule isolation.

Protein content. This was measured according to Lowry et al. (1951), using bovine serum albumin as a standard.

Electron microscopy. Electron micrographs of membranes were prepared on formvar-coated grids by negative staining with phosphotungstic acid (Brenner \& Horne, 1959). Thin sections of bacteroid suspensions were prepared after mixing the suspension with $2 \%(\mathrm{w} / \mathrm{v})$ agar and fixation as described by Kijne (1975).

Other methods. Membranes were centrifuged on a sucrose gradient according to Osborn et al. (1972) and bacterial outer membrane was identified by heptose determinations according to Dische (1962).

\section{RESULTS}

\section{Preparation of bacteroid fractions}

After the homogenization of root nodules, many bacteroids were still retained in clumps of cytoplasm. This was especially true for very young ( 9 day) pea nodules. Only after washing were bacteroids completely released, and a supernatant containing most of the plant cell membranes was separated from the bacteroid pellet by centrifuging. The membranes released on washing the bacteroid pellet (Fig. I) are probably not outer membranes of the bacteroid cell wall since heptose determinations were negative and no material was found in sucrose gradients at the characteristic density of bacteroid membranes.

The bacteroid suspension was practically free from starch granules and plant debris 


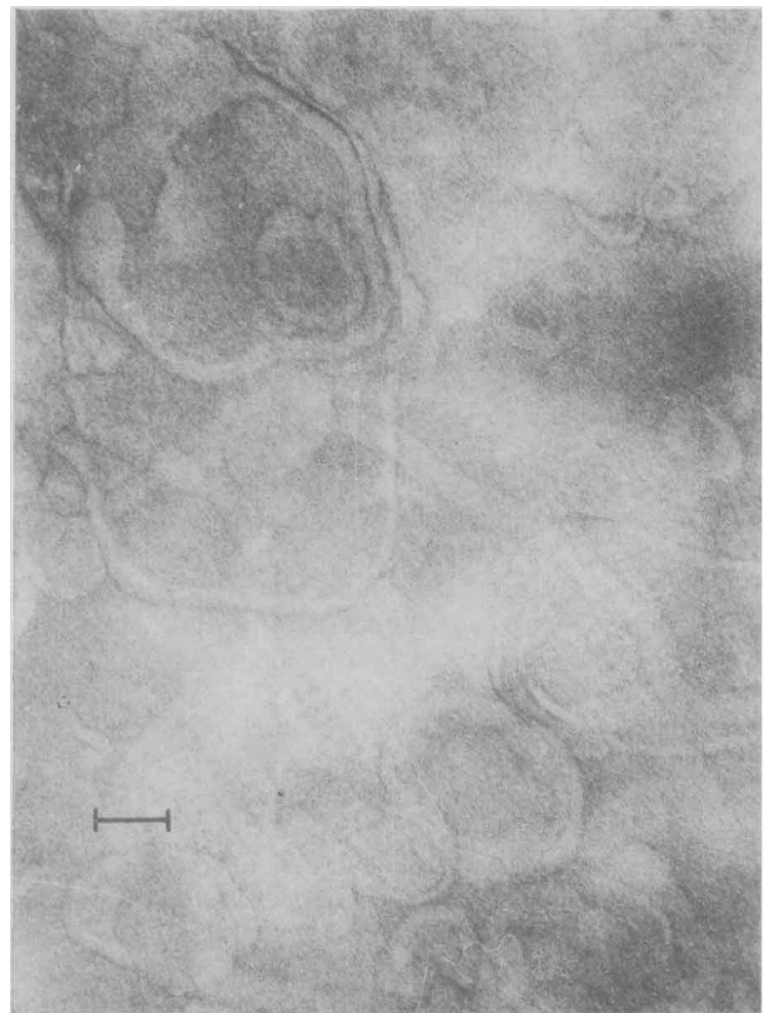

Fig. I

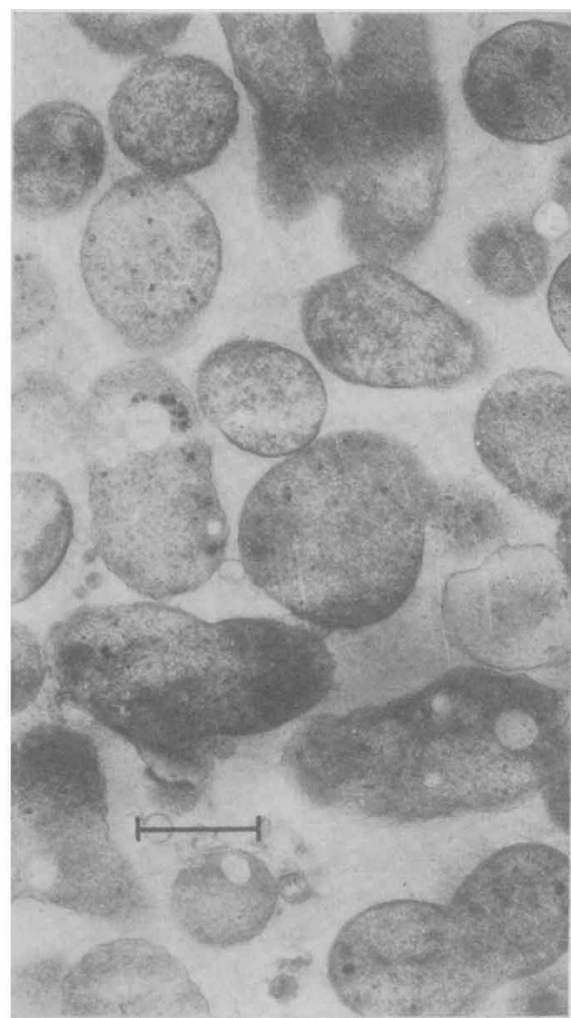

Fig. 2

Fig. 1. Electron micrograph of negatively-stained material released in the first wash supernatant on washing pea bacteroids obtained by homogenization. Bar marker represents $0.1 \mu \mathrm{m}$.

Fig. 2. Electron micrograph of the preparation of pea bacteroids used in the experiments. Bar marker represents I $\mu \mathrm{m}$.

when examined by phase contrast microscopy. No starch granules or plastids, and only small amounts of membranous material, were observed by electron microscopy (Fig. 2). Lysozyme incubation followed by osmotic shock caused a rapid decrease in the absorbance of lupin and pea bacteroid suspensions (Fig. 3). Pea and lupin bacteroids were also easily ruptured by sonication whereas free-living $R$. leguminosarum was not disrupted under the conditions used. Protein recovery from all treatments was similar, indicating that no cell material was lost.

\section{Location of enzyme activities}

The measured activities of nitrogenase in fractions of lupin and pea bacteroids varied slightly but the overall distribution pattern (Table I) was similar in different experiments. The activity of each fraction was determined at several protein concentrations since each had an optimum protein concentration (Fig. 4). Intact pea and lupin bacteroids had low nitrogenase activities unless oxygen and succinate were used as substrates in place of ATP and dithionite.

Lupin bacteroids became permeable to ATP and dithionite on treatment with lysozyme, without an osmotic shock treatment (Table I). About the same total activity was found as when nitrogenase was released by sonication or by osmotic shock following lysozyme treatment. The distribution of nitrogenase throughout the fractions examined supports the view 


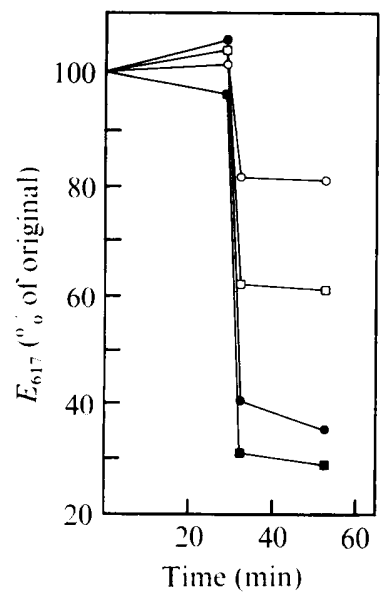

Fig. 3

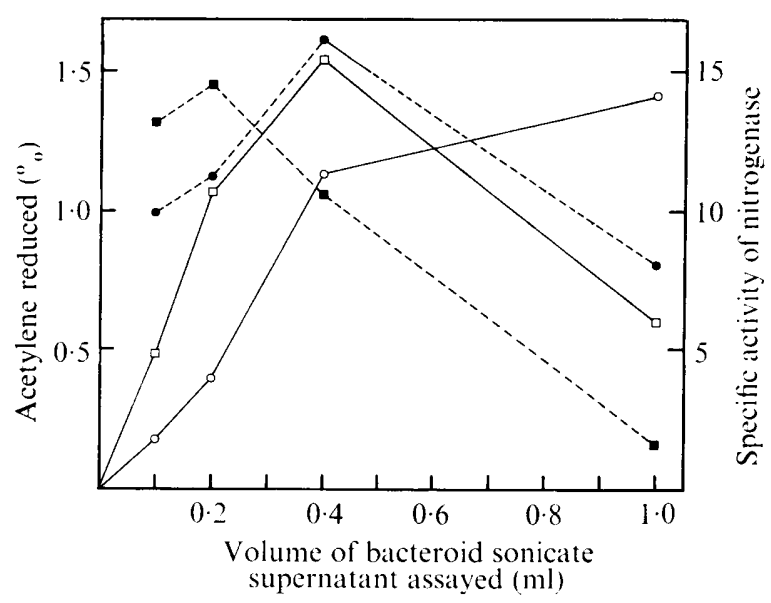

Fig. 4

Fig. 3. Effect of osmotic shock on the absorbance $\left(E_{617}\right)$ of bacteroid suspension after $30 \mathrm{~min}$ incubation in the presence $(\boldsymbol{Q}, \boldsymbol{\square})$ or absence $(\bigcirc, \square)$ of lysozyme: $\boldsymbol{O}, \bigcirc R$. lupini bacteroids; $\square, \square R$. leguminosarum bacteroids. Note that the ordinate scale starts at $20 \%$.

Fig. 4. Effect of enzyme concentration and incubation time on nitrogenase assay. A bacteroid sonicate supernatant containing $16.3 \mathrm{mg}$ protein $\mathrm{ml}^{-1}$ was used. Acetylene reduced: $\bigcirc$, in the first $9 \mathrm{~min} ; \square$, in the next $20 \mathrm{~min}$ of reaction. Specific activity of nitrogenase $\left[\mathrm{nmol} \mathrm{C}_{2} \mathrm{H}_{2}\right.$ reduced $\left.\min ^{-1}(\mathrm{mg} \text { protein })^{-1}\right]: \mathcal{O}$, in the first $9 \mathrm{~min} ; \boldsymbol{\nabla}$, in the next $20 \mathrm{~min}$ of reaction.

Table I. Distribution of nitrogenase in fractions of lupin and pea bacteroids

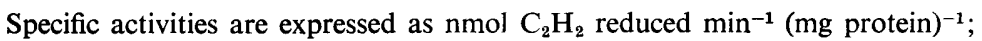
total activities are expressed as nmol $\mathrm{C}_{2} \mathrm{H}_{2}$ reduced $\min ^{-1}$.

Fraction

Bacteroid suspension

Bacteroid sonicate supernatant

Bacteroid sonicate pellet

Lysozyme incubation suspension

Lysozyme incubation supernatant

Lysozyme-shock supernatant

Lysozyme-shock pellet

Lysozyme-shock sonication supernatant

Lysozyme-shock sonication pellet

\begin{tabular}{|c|c|}
\hline \multicolumn{2}{|c|}{ Lupin } \\
\hline $\begin{array}{l}\text { Specific } \\
\text { activity }\end{array}$ & $\begin{array}{c}\text { Total } \\
\text { activity }\end{array}$ \\
\hline 0.2 & 237 \\
\hline 20.9 & 7768 \\
\hline 0 & 0 \\
\hline 8.0 & $645^{8}$ \\
\hline $5 \cdot 5$ & I 479 \\
\hline I 3.9 & 3 I 56 \\
\hline 0 & 0 \\
\hline 0 & 0 \\
\hline 0 & 0 \\
\hline
\end{tabular}

\begin{tabular}{|c|c|}
\hline \multicolumn{2}{|c|}{ Pea } \\
\hline $\begin{array}{l}\text { Specific } \\
\text { activity }\end{array}$ & $\begin{array}{c}\text { Total } \\
\text { activity }\end{array}$ \\
\hline$*$ & $*$ \\
\hline $2 I \cdot 0$ & I 733 \\
\hline 0 & 0 \\
\hline ND & ND \\
\hline I $2 \cdot 5$ & $3 I$ \\
\hline $72 \cdot I$ & 2631 \\
\hline ND & ND \\
\hline$I \cdot 5$ & 42 \\
\hline 0 & 0 \\
\hline
\end{tabular}

ND, Not determined. * Very low irreproducible values were recorded.

that nitrogenase is in the soluble cytoplasm of bacteroids, although in lupin bacteroids it is quite accessible to substrates after lysozyme treatment.

Table 2 shows the specific and total activities of glutamine synthetase in nodule and bacteroid fractions of lupins and green peas. As crude extracts of bacteroids possessed a high ATPase activity which interfered with the assay of Shapiro \& Stadtman (I970) for glutamine synthetase (I. Kennedy \& S. Stone, unpublished results), we followed the formation of $\gamma$-glutamyl hydroxamate from glutamate in the presence of $\mathrm{Mg}^{2+}$ and ATP. The synthetase activity of glutamine synthetase in pea bacteroids was too low to measure in the bacteroid fractions; that of the nodule cytosol and first wash supernatant was 20 to $30 \%$ of 


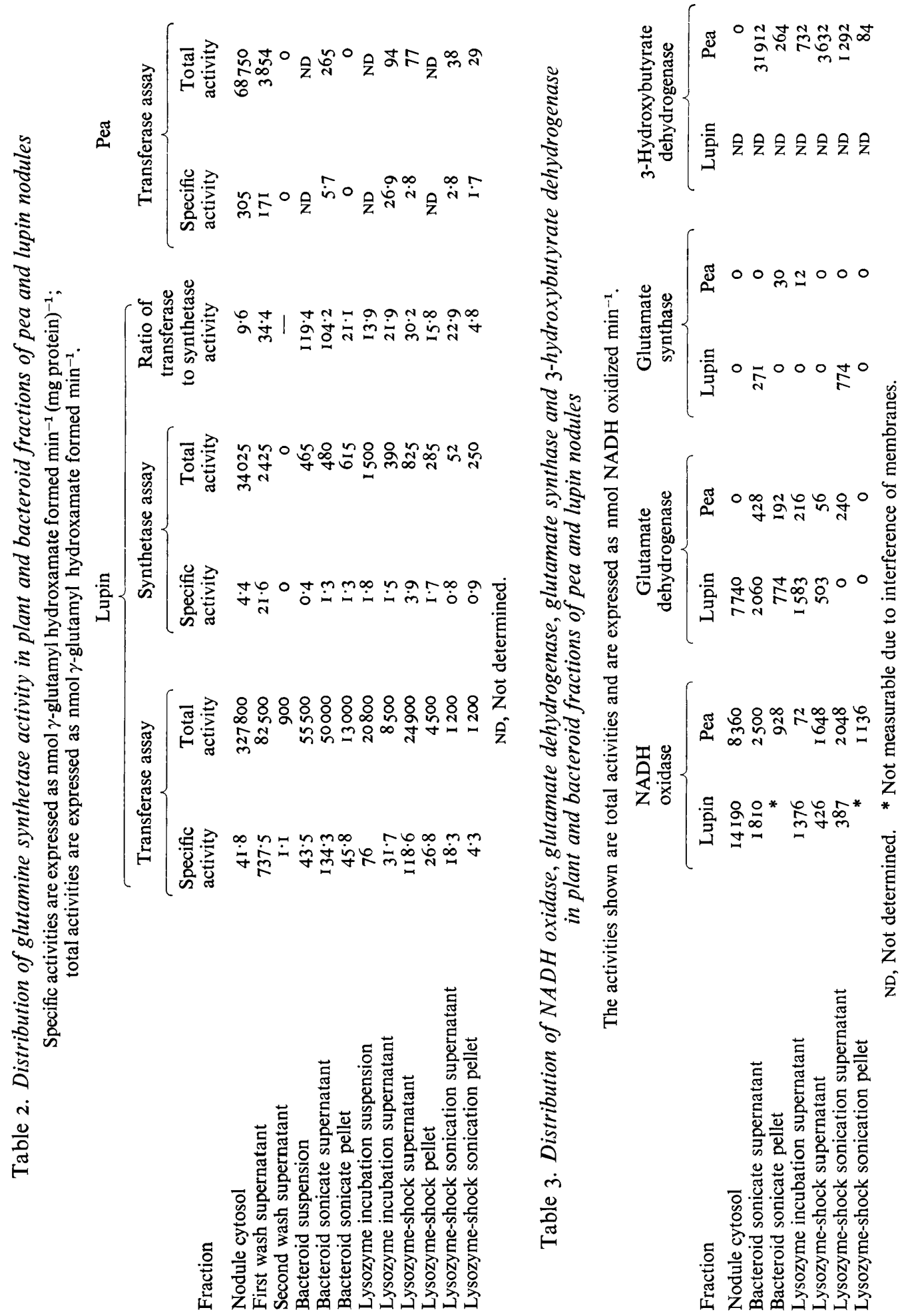


the transferase activity. In lupin nodules approximately $75 \%$ of the transferase and $95 \%$ of synthetase activity was localized in the nodule cytosol, in agreement with the results of Brown \& Dilworth (1975). A high specific activity was found in the first wash supernatant from both pea and lupin nodules. In lupin the ratio of transferase to synthetase activity in this fraction differed from that found in the nodule cytosol, suggesting that glutamine synthetase located very close to the bacteroids and released by the first wash is in a different state to that found in the nodule cytosol. In peas, about $99 \%$ of the transferase activity was located within the nodule cytosol.

Most of the glutamine synthetase was localized in the cytoplasm of lupin bacteroids, as indicated by the activity released into the lysozyme-shock supernatant. In contrast, pea bacteroids released about one-third of their total glutamine synthetase activity on incubation with lysozyme, a further $40 \%$ was released on osmotic shock treatment and the rest remained membrane-bound. The release of enzyme into the lysozyme incubation supernatant of pea bacteroids was not due to lysis by this treatment, since only $13 \%$ of the total 3-hydroxybutyrate dehydrogenase activity, a soluble enzyme in pea bacteroids, was released compared with $39 \%$ of the total bacteroid glutamine synthetase.

High levels of glutamate dehydrogenase were present in lupin nodule cytosol, but this enzyme was absent from the cytosol of pea nodules (Table 3). Up to $60 \%$ of the total activity leaked out of lupin bacteroids on treatment with lysozyme and approximately $40 \%$ leaked out of pea bacteroids. A little activity remained membrane-bound in pea bacteroids but in lupin all residual activity was released after osmotic shock.

Glutamate synthase was NADH-linked in lupin bacteroids, as was found by Brown \& Dilworth (1975). The enzyme was present only in very small amounts in pea bacteroids (Table 3), in agreement with the results of Brown \& Dilworth (1975) and Kurz, Rokosh \& LaRue (1975). To determine optimal assay conditions for these enzymes both NADH and NADPH were tested. When extracts were passed through a Sephadex G-25 column to remove possible inhibitors no increase in activity was observed. In lupin bacteroids, glutamate synthase was released in the bacteroid sonicate supernatant and in the lysozyme-shock sonication supernatant, indicative of a loosely membrane-bound localization.

NADH oxidase, chosen as a marker enzyme for membranes, was present in all fractions of lupin and pea nodules (Table 3), suggesting that a soluble form of the enzyme occurred. 3-Hydroxybutyrate dehydrogenase was present only as a soluble enzyme, since no significant activity was found in the bacteroid sonicate pellet (Table 3 ).

\section{DISCUSSION}

The total activity of nitrogenase in extracts of pea bacteroids was similar to the activity reported for the intact root system $\left(2.5 \mu \mathrm{mol} \mathrm{h}^{-1}\right.$ per plant) by Planqué \& van Brussel (1976). Sonication or lysozyme treatment gave a good recovery of nitrogenase from bacteroids. Detached root systems of $2 \mathrm{I}$-day-old plants reduced acetylene at a constant rate of 30 to $45 \mathrm{nmol} \mathrm{m^{-1 }}$ per plant for up to $2 \mathrm{~h}$, compared with a nitrogenase activity in vitro of

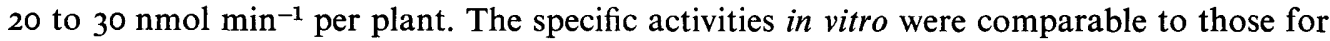
cell-free soybean bacteroids (Dunn \& Klucas, 1973) but were much lower than those reported by Kurz et al. (1975) for intact peas and vetches. The nitrogenase was non-particulate, in agreement with reports for nitrogenase of Klebsiella pneumoniae and Clostridium pasteurianum (Ljones, 1974). Particulate nitrogenases have been reported from ' $M y c o-$ bacterium' flavum (Biggins \& Postgate, 1969) and from Azotobacter vinelandii (Bulen, Burns \& LeComte, 1964) although the latter has been questioned by Oppenheim et al. (1970) who used osmotic lysis instead of a French pressure cell to disrupt the organism. The soluble nature of Rhizobium nitrogenase is also supported by the rapid release of nitrogenase on incubation of bacteroids with $\mathrm{I} \%$ Triton X-100; this also released $95 \%$ of the total 3-hydroxybutyrate dehydrogenase activity (de Vries, unpublished results). 
The total transferase activity of glutamine synthetase in pea bacteroids was negligible compared with that of the nodule cytosol (less than $0.2 \%$ ). However, in lupin bacteroids the total transferase and synthetase activities of glutamine synthetase were much higher. In fractions prepared by sonication or lysozyme incubation, levels were $17 \%$ and $10 \%$ respectively for transferase activity and 3 to $4 \%$ for synthetase activity (as percentages of nodule cytosol activity). This relative amount of total activity is not affected by the presence of non-nodulated root material, since root tissue of lupin does not contain a highly active glutamine synthetase while the nodule tissue does (Robertson et al., 1975a). These authors found synthetase activities similar to those reported in this paper.

The transferase activity in lupin bacteroid sonicate supernatant was Ioo times greater than the synthetase activity, indicating that most of the glutamine synthetase is in the biosynthetically inactive form. The absence of synthetase activity in pea bacteroids supports the hypothesis of Brown \& Dilworth (1975) that glutamine synthetase is not involved in $\mathrm{NH}_{4}{ }^{+}$assimilation inside the bacteroids. They suggested that the low activity of bacteroids is due to absorbtion of enzyme from the nodule cytosol. The different ratios of transferase to synthetase activity in lupin nodule cytosol and bacteroid fractions reported here are inconsistent with this view. We are aware of the danger of comparing the ratios of synthetase and transferase activities between plant and bacteroid glutamine synthetases as considerable differences have been reported for the optimal assay conditions of the two enzymes (MacParland et al., 1976). Care must also be taken in interpreting the $\gamma$-glutamyl transferase activity determined in this assay since it can be separated into several proteins by isoelectric focusing (Darrow, Knotts \& Jarrel, 1976).

Glutamine synthetase in bacteroid fractions showed a predominantly cytoplasmic localization, as most of the total activity was released either on sonication or on lysozyme lysis and very little activity remained membrane-bound. The leakage of some enzyme from the bacteroids on incubation might indicate a superficial localization of part of the enzyme. The high specific activity of the synthetase found in the first wash supernatant is consistent with the view that most of the newly-fixed nitrogen is assimilated between the bacteroid and the host membrane envelope.

Glutamate synthase activities were lower than glutamine synthetase activities in lupin bacteroids and were virtually absent in pea bacteroids. Kurz et al. (1975) reported very low glutamate synthase levels in bacteroids of Rhizobium leguminosarum and doubted the presence of the enzyme. This suggests that the glutamine synthetase-glutamate synthase pathway does not operate within the bacteroids.

Although assimilation of newly-fixed $\mathrm{NH}_{4}{ }^{+}$will take place mainly outside the bacteroids (Lea \& Miflin, 1976; Scott et al., 1976) some assimilation inside the bacteroids cannot be ruled out completely. The amount of $\mathrm{N}_{2}$ reduced, calculated as described by Bergersen (1970) from the acetylene reduction data (Table I), can be compared with the glutamate dehydrogenase activities. For lupin bacteroids we calculated that $14.4 \mathrm{nmol} \mathrm{NH}_{3}$ were formed and $27 \mathrm{nmol}$ NADH were oxidized per $\mathrm{min}^{-1}$ per plant. For pea bacteroids the values were $7 \cdot 7$ and $x \cdot 3$ respectively. From these values one could conclude that some ammonia assimilation occurred inside the bacteroids. However, it may be argued that the assay conditions are not physiological, in particular for glutamate dehydrogenase for which apparent $K_{\mathrm{m}}$ values for $\mathrm{NH}_{4}{ }^{+}$of $13.9 \mathrm{~mm}$ (Brown \& Dilworth, 1975) and $73 \mathrm{~mm}$ (Dunn \& Klucas, 1973) have been reported. The rate of efflux of ammonia from the bacteroids will determine whether bacteroid glutamate dehydrogenase can play an important role in the assimilation of the newly-fixed $\mathrm{N}_{2}$. In pea bacteroids no significantly active assimilatory pathway could be detected.

In pea and lupin bacteroids only 30 to $50 \%$ of the total glutamine synthetase activity and Io to $25 \%$ of the total glutamate dehydrogenase activity was clearly cytoplasmic. The remaining activity was either membrane-bound or leaked out on incubation with lysozyme, indicative of a superficial or periplasmic localization. The localization of nitrogenase in the cytoplasm might lead to a relative high ammonia concentration inside the bacteroids. 
The authors wish to thank the Netherlands Organization for the Advancement of Pure Research (Z.W.O.) and the Foundation for Biological Research (B.I.O.N.) for financial support, Annelies Burgers and Jacques J. van Nierop for skilful technical assistance, Hans Staal for the electron microscopy of isolated bacteroids and Dr R. R. Eady for his valuable comments on the manuscript.

\section{REFERENCES}

Akkermans, A. D. L. (1971). Nitrogen fixation and nodulation of Alnus and Hippophae under natural conditions. Ph.D. thesis, University of Leiden, The Netherlands.

Bergersen, F. J. (1970). The quantitative relationship between nitrogen fixation and the acetylene reduction assay. Australian Journal of Biological Sciences 23, 1015-I025.

Biggins, D. R. \& Postgate, J. R. (I969). Nitrogen fixation by cultures and cell-free extracts of Mycobacterium flavum 301. Journal of General Microbiology 56, I8I-193.

Brenner, S. \& Horne, R. W. (I959). A negative staining method for high resolution electron microscopy of viruses. Biochimica et biophysica acta 34, 103-1 IO.

Brown, C. M. \& Dilworth, M. J. (1975). Ammonia assimilation by Rhizobium cultures and bacteroids. Journal of General Microbiology 86, 39-48.

BRUSSEL, A. A. N. VAN (1973). The cell wall of Rhizobium leguminosarum Frank. Ph.D. thesis, University of Leiden, The Netherlands.

Brussel, A. A. N. van, Planqué, K. \& Quispel, A. (I977). The wall of Rhizobium leguminosarum in bacteroids and free-living forms. Journal of General Microbiology ror, 5 I-56.

Bulen, W. A., Burns, R. C. \& LeComte, J. R. (I964). Nitrogen fixation: cell-free system with extracts of Azotobacter. Biochemical and Biophysical Research Communications 17, 265.

Darrow, R. A., KNotTs, R. R. \& Jarrel, S. O. (1976). The significance of $\gamma$-glutamyl transferase activity in extracts of enteric bacteria, root nodule bacteria and isolated bacteroids. Plant Physiology 57, 70, report 366 .

Dische, Z. (1962). Methods in Carbohydrate Chemistry $\mathbf{r}, 980$.

DunN, S. D. \& Klucas, R. V. (1973). Studies on possible routes of ammonia assimilation in soybean root nodule bacteroids. Canadian Journal of Microbiology r9, I493-I499.

Grimes, H. \& FotTrell, P. F. (I966). Enzymes involved in glutamate metabolism in legume root nodules. Nature, London 212, 295-296.

KENNEDY, I. R. (I966a). Primary products of symbiotic nitrogen fixation. I. Short-term exposure of Serradella nodules to ${ }^{15} \mathrm{~N}_{2}$. Biochimica et biophysica acta 130, 285-294.

KENNEDY, I. R. (I $966 b)$. Primary products of symbiotic nitrogen fixation. II. Pulse-labelling of Serradella nodules with ${ }^{15} \mathrm{~N}_{2}$. Biochimica et biophysica acta 130, 295-303.

KENNEDY, I. R. (I973). Glutamine synthetase/ glutamate synthase for ammonia assimilation in symbiotic nitrogen fixation. Proceedings of the Australian Biochemical Society 6, 33.
Kennedy, I. R., Parker, C. A. \& Kidby, D. K., 1966. The probable site of nitrogen fixation in root nodules of Ornithopus sativus. Biochimica et biophysica acta 130, 517-519.

KIJNE, J. W. (I975). The fine structure of pea root nodules. I. Vacuolar changes after endocytotic host cell infection by Rhizobium leguminosarum. Physiological Plant Pathology 5, 75-79.

Kurz, W. G., Rokosh, D. A. \& LaRue, T. A. (1975). Enzymes of ammonia assimilation in Rhizobium leguminosarum bacteroids. Canadian Journal of Microbiology 21, I009-10I 2.

LEA, P. J. \& Miflin, B. J. (1976). The pathway of nitrogen assimilation in plants. Phytochemistry I5, 873-885.

LJONES, T. (1974). In The Biology of Nitrogen Fixation, pp. 617-638. Edited by A. Quispel. New York: North-Holland/Elsevier.

Lowry, O. H., Rosebrough, N. J., Farr, A. L. \& RANDALL, R. J. (I95I). Protein measurement with the Folin phenol reagent. Journal of Biological Chemistry 193, 265-275.

MacParland, R. H., Guevara, J. G., Becker, R. R. \& EVANS, H. J. (I976). The purification and properties of the glutamine synthetase of the cytosol of soya bean root nodules. Biochemical Journal I53, 597-606.

Nagatani, H., Shimizu, M. \& Valentine, R. C. (I97I). The mechanism of ammonia assimilation in nitrogen fixing bacteria. Archiv für Mikrobiologie 79, 164-175.

O'Gara, F. \& Shanmugam, K. T. (i976). Regulation of nitrogen fixation by Rhizobia. Export of fixed $\mathrm{N}_{2}$ as $\mathrm{NH}_{4}{ }^{+}$. Biochimica et biophysica acta 437, 313-32 I.

OpPenheim, J., Fischer, R. J., Wilson, P. \& Marcus, L. (1970). Properties of a soluble nitrogenase in Azotobacter. Journal of Bacteriology Ior, 292-296.

Osborn, M. J., Gander, J. E., Parasi, E. \& Carson, J. (I972). Mechanism and assembly of the outer membrane of Salmonella typhimurium. Journal of Biological Chemistry 247, 3962-3972.

Planqué, K. \& Van Brussel, A. A. N. (1976). An improved large scale isolation procedure for bacteroids of Rhizobium leguminosarum. Plant and Soil, 45, 309-3 I 5.

Robertson, J. G., FARnden, K. J. F., Warburton, M. P. \& BANKS, J. M. (I975a). Induction of glutamine synthetase during nodule development in lupin. Australian Journal of Plant Physiology 2, 265-272.

Robertson, J. G., Warburton, M. P. \& Farnden, K. J. F. (1975b). Induction of glutamate synthase during nodule development in lupins. FEBS Letters 55, 33-37. 
Rowe, W. B., Ronzio, R. A., Wellner, V. P. \& Meister, A. (1970). Glutamine synthetase (sheep brain). Methods in Enzymology, XVIIA, 900-910.

ScotT, D. B., Farnden, K. J. F. \& Robertson, J. G. F. (1976). Ammonia assimilation in lupin nodules. Nature, London 263, 703-706.

Shanmugam, K. T. \& Valentine, R. C. (I975). Molecular biology of nitrogen fixation. Science 187, 919-924.

Shapiro, B. M. \& Stadtman, E. R. (I970). Glutamine synthetase (Escherichia coli). Methods in Enzymology XVIIA, 910-922.

Streicher, S. L., Shanmugan, K. T., Ausubel, F. Morandi, C. \& GoldberG, R. B. (I974). Regulation of nitrogen fixation in Klebsiella pneumoniae: evidence for a role of glutamine synthetase as a regulator of nitrogenase synthesis. Journal of Bacteriology 120, 81 5-821.

Tempest, D. W., Meers, J. L. \& Brown, C. M. (1973). Glutamate synthetase (GOGAT); a key enzyme in the assimilation of ammonia by prokaryotic organisms. In The Enzymes of Glutamine Metabolism, pp. I67-182. Edited by S. Prusiner \& E. R. Stadtman. New York: Academic Press.

TubB, R. S. (I974). Glutamine synthetase and ammonia regulation of nitrogenase synthesis in Klebsiella. Nature, London 25I, 48I-485.

Yates, M. G. \& Planqué, K. (I975). Nitrogenase from Azotobacter chroococcum. Purification and properties of the component proteins. European Journal of Biochemistry 6o, 467-476. 